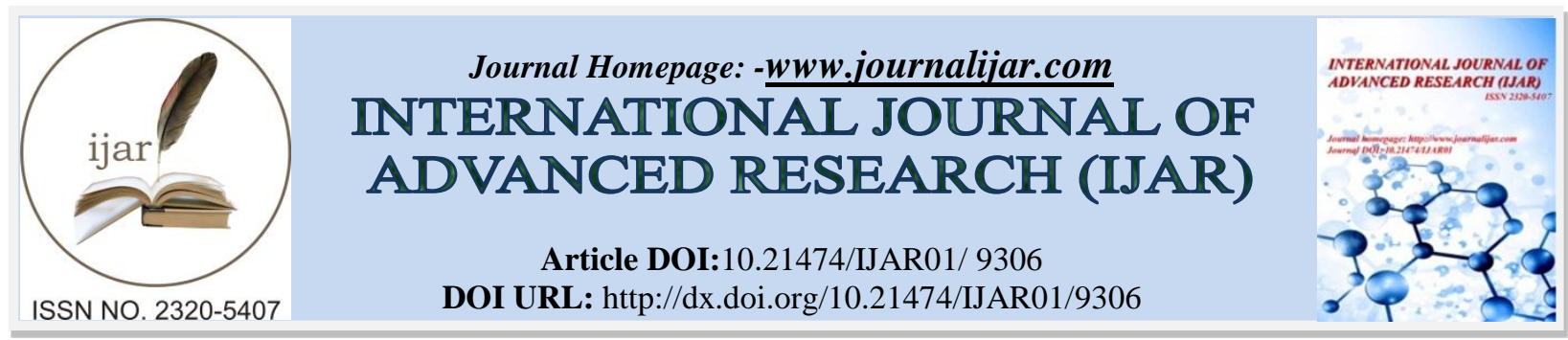

RESEARCH ARTICLE

\title{
A NEW REACTOR GEOMETRY TO TREATMENT IN SCALE OF BIOMEDICAL SURFACES BY PLASMA ELECTROLYTIC OXIDATION.
}

\author{
Ana Karenina de Oliveira Paiva, Arlindo Balbino Nascimento Neto, Andréa Santos Pinheiro de Melo, Ângelo \\ Roncalli Oliveira Guerra, Ricardo Alexsandro de Medeiros Valentim and Custódio Leolpodino de Brito \\ Guerra Neto. \\ Federal University of Rio Grande do Norte, Natal/RN - Brazil.
}

\section{Manuscript Info}

\section{Manuscript History}

Received: 15 April 2019

Final Accepted: 17 May 2019

Published: June 2019

Key words:-

New reactor geometry; Plasma

Electrolytic Oxidation (PEO); PEO

scale; Biomedical surfaces.

\begin{abstract}
The state of the art report many studies seeking for biocompatible materials for manufacturing and processing of implants, mainly, for orthopedic and dental care. A wide spectrum of surface modification techniques are available, such as chemical vapor deposition, anodizing, plasma spraying and plasma electrolytic oxidation (PEO). Among these techniques, PEO is an attractive technique for biomedical applications once that its characteristics favor the osseointegration. Hitherto, the literature reports that all designed reactors are limited to processing a single sample at a time. A second limitation of the existing reactors, in terms of geometry, is the difficulty to obtain a uniform treatment on poly faceted pieces. In this context, the present study aimed to design, develop and manufacture a new reactor geometry to surface treatments, scaling it and with better uniformity. The prototype validation was performed through treatments of cylindrical titanium samples in electrolytic bath for 1, 8 and 16 minutes. To characterize the thickness of the coating on the samples, optical microscopy and scanning electronic microscopy were used. For the coating chemical, characterization technique such as energy dispersive spectroscopy, were applied. The wettability study was performed using the sessile drop method. The new reactor designed geometry presented promising results once that it was capable to produce homogeneous, porous hydrophilic coatings, and mechanical resistance to contact. The new reactor has shown ability to scale production. Finally, it is believed that there is a reduction in production costs because the same solution is used to a set of samples.
\end{abstract}

Copy Right, IJAR, 2019,. All rights reserved.

\section{Introduction:-}

Titanium (Ti) and its alloys, due to their unique combination of low density, high specific resistance to the effects caused by fluids present in the human body and biocompatibility, are widely used in automotive, aerospace, naval and biomedical engineering (MU et al., 2013) (SHOKOUHFAR; ALLAHKA-RAM, 2016). Within this area, titanium and its alloys play an important role in orthopedic and odontological rehabilitation (WILLIAMSON et al., 2015). It also features high mechanical strength, high thermal stability and good formability. The titanium metal 
oxidizes spontaneously and immediately when exposed to air at room temperature, forming a thin passive layer, which protects it from oxidation and corrosion (MOHSENI; ZALNEZHAD; BUSHROA, 2014) (HENEGAR et al., 2016). However, this native oxide layer can be lost quickly in harsh environments. Consequently, an appropriate surface modification for titanium-based alloys is necessary in order to improve its properties as well as osseointegration and bioactivity (YAVARI et al., 2016) (LIU et al., 2016) (AKTUĞ et al., 2017). Research have revealed that the velocity, strength and degree of osseointegration depend, mainly, on the superficial properties of implants, among which chemistry, physics, topography and wettability are known as very important factors (QIAO et Al., 2016) (BANAKH et al., 2016) (KHANMOHAMMADI et al., 2017). Due to the importance of obtaining surfaces that optimize osseointegration, a wide range of surface modification techniques have been applied and studied.

There are several engineering methods to promote surface modifications, such as: corrosion/acid oxidation, cold plasma irradiation, laser, photolithography, sol-gel, plasma-immersion ion implantation, low pressure plasma spraying, anodizing or electrochemical deposition and plasma electrolytic oxidation (PEO). All these techniques have advantages and limitations (WANG et al., 2015) (GOVINDARAJAN; SHANDAS, 2014) (QIU et al., 2014) (ZHOU et al., 2016) (TRAN; NGUYEN, 2017).

Among all techniques used for engineering surfaces, those based on plasma technology have shown to be extremely efficient to improve surface properties (ZHAO; YEUNG CHU, 2014).

Within the state of the art plasma techniques, Plasma Electrolytic Oxidation (PEO) have been highlighted by the scientific community once that it is environmental friendly and highly flexible technique capable to form welladhered oxide films with controlled morphology and composition ( HARIPRASAD et al., 2016) (SHOKOUHFAR; ALLAHKARAM, 2016) (LI et al., 2017a) on metallic surfaces with complex geometry, such as dental implants (KHAN et al., 2014). Another the features of PEO is the capacity to allow the adaptation of surface properties (YEUNG, 2016) working at atmospheric pressure and low treatment time. The PEO can also perform antibacterial coatings with the addition of nano silver particles (YU; CHEN CAO, 2012). Thus, PEO presents itself as an attractive technique for biomedical applications once that its characteristics favor osseointegration (SOWA et al., 2015) (YAVARI et al., 2016) (AKTUĞ et al., 2017).

Although numerous studies have been conducted on the optimization of processing parameters, these are focused on the effects of one or two variables that influence the behavior of plasma discharge and/or correlation between both parameters to provide the morphology and composition of the desired PEO phase. Researches showed the influence of configuration and disposition of the electrodes in the PEO coating formation. However, it is not known the influence of coatings when they are performed for more than one element. Currently, based in the researched literature, all reactors designed are limited to treat a single sample at a time. A second limitation of the existing reactors, in terms of geometry, is the difficulty of obtaining a uniform treatment in poly faceted pieces. In order to solve these problems, this work designed, developed and manufactured a new reactor geometry for superficial treatments, scaling it and with better uniformity. After these steps, the equipment was validated by different techniques of chemical, physical and structural characterization. 


\section{Methodology:-}

In this project, an adaptation of the Systems Engineering methodology proposed by Gerhard Pahl (PAHL, 2013) was applied. Thus, following this methodology the process of development and design was divided into phases, denominated: product planning and task clarification (informational definition of requirements); conceive (carry out the problem abstraction, study of principles, functions and preliminary definition); configuration (definition of layout, geometry, topology, and materials) and drill-down (production technology definition). Thus, for the PEO reactor presented in this article, initially, the approach consisted of planning, studying, conceiving and detailing the design of a PEO reactor for poly faceted pieces, and scaling it. Then, the mechanical parts were manufactured and assembled in the new configuration for the reactor of ceramic deposition on metals by Plasma Electrolytic Oxidation (PEO). Subsequently, a ceramic film was deposited on the titanium rods, and chemical, physical and mechanical characterizations analysis of the film were carried out. In addition, the morphology of the coatings produced by the new PEO equipment performed in this study was studied. Fig 1 shows the flowchart of the methodology and other stages of this work.

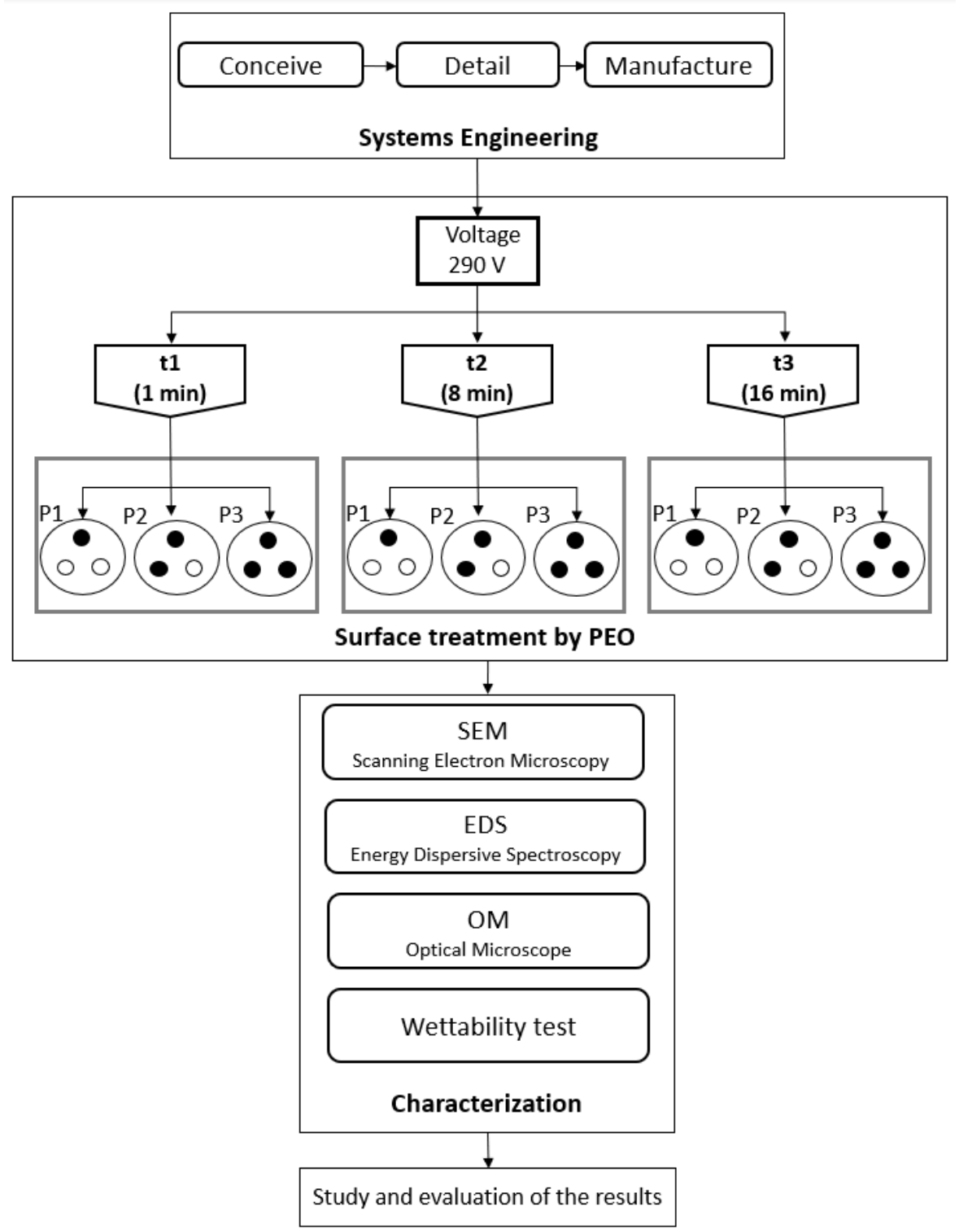

Fig 1:-Flowchart of the System Engineering methodology adapted from PAHL (2013). 


\section{Configuration of PEO reactor}

To perform the 2D and 3D modeling of the PEO equipment used for this work, the software SolidWorks ${ }^{1}$ was applied.

The ceramic coated via PEO titanium rods equipment used in this work had 14 types of parts, as can be seen in Fig 2. In addition, Fig 2 (a) represents the isometric view of the assembled PEO reactor, Fig 2 (b) shows an exploded view of the PEO reactor that evidences the constituent parts of the PEO reactor. The constituent parts of the PEO reactor are nominated by item.

The item (1) represents a $600 \mathrm{ml}$ beaker used as a reservoir for the electrolyte solution. This beaker contains an input and outlet channel to provide the continuous flow of the electrolyte during the treatments. The item (2) represents the column rod with $12.7 \mathrm{~mm}$ diameter and $300 \mathrm{~mm}$ long, stainless steel 304. The item (3) represents the beam rod with $19.05 \mathrm{~mm}$ diameter and $180 \mathrm{~mm}$ long, stainless steel 304. The pieces (2) and (3) were used as support column and beam of the reactors, respectively. The items (4) and (5) represent the Screw (M6x25mm) and the Butterfly Nut (M6) of stainless steel. The beam (3) moves through the column (2) to adjust the best height. When the best height is achieved, the beam (3) can be fixed by the screw and nut assembly that presses the beam (3) through the column (2) and locks the system. The item (6) represents an endless screw M6x200 mm of stainless steel with a handle to assist the height adjustment. This is to perform a millimetric adjustment of the rector height within the electrolytic solution, from the beam (3) that has an internal thread M8x1.25 mm. The item (7) represents the insulating PA (sample holder) of nytanyl which has $80 \mathrm{~mm}$ diameter and $10 \mathrm{~mm}$ of length. This has three passing holes $(8 \mathrm{~mm}$ in diameter) for fixing the sample holder (8), a passing hole (8 $\mathrm{mm}$ in diameter) to fix the endless screw (6) and three passing holes $(3 \mathrm{~mm}$ in diameter) for the passage of the electrical cables used for feeding the reactors . The insulating PA (7) fix the sample holder. The item (8) represents the sample holder with M8 nut and $100 \mathrm{~mm}$ length of stainless steel. The item (9) represents the samples with $3 \mathrm{~mm}$ diameter and $25 \mathrm{~mm}$ length of titanium used in this work. The item (10) represents the three headless internal hexagon screws $1.5 \mathrm{~mm}$ in diameter and $3 \mathrm{~mm}$ in length of stainless steel, used to fix the titanium samples in the sample holder. Item 11 represents the connection sleeve with $20 \mathrm{~mm}$ diameter and $15 \mathrm{~mm}$ length with an internal nut M8 and $1.25 \mathrm{~mm}$ length of made from stainless steel, used to space the insulating PA (7) and insulating CL (12). Between this space, the electrical contacts were carried out with the power source of the equipment. The item (12) represents the nytanyl insulating CL which is $80 \mathrm{~mm}$ in diameter and $10 \mathrm{~mm}$ in length. It has three passing holes (15.9 mm diameter) for fixing the pipes (14) and a passing hole ( $8 \mathrm{~mm}$ in diameter) to fix the endless screw (6). The letters CL are the acronyms for pipe since the insulating CL (12) fixes the pipes (14). Item 13 represents the nytanyl insulating CA that has a stagnated external diameter of $16 \mathrm{~mm}$ in diameter and $5 \mathrm{~mm}$ in length, $14 \mathrm{~mm}$ in diameter and $45 \mathrm{~mm}$ in length and internal nut M8 and $1.25 \mathrm{~mm}$ in length. The item (14) represents the pipe of $16 \mathrm{~mm}$ in diameter and $100 \mathrm{~mm}$ in length with wall thickness of 1 $\mathrm{mm}$ of stainless steel. Thus, the PEO equipment designed and manufactured, used for this work, presents three reactors conFigd to coat cylindrical metal samples.
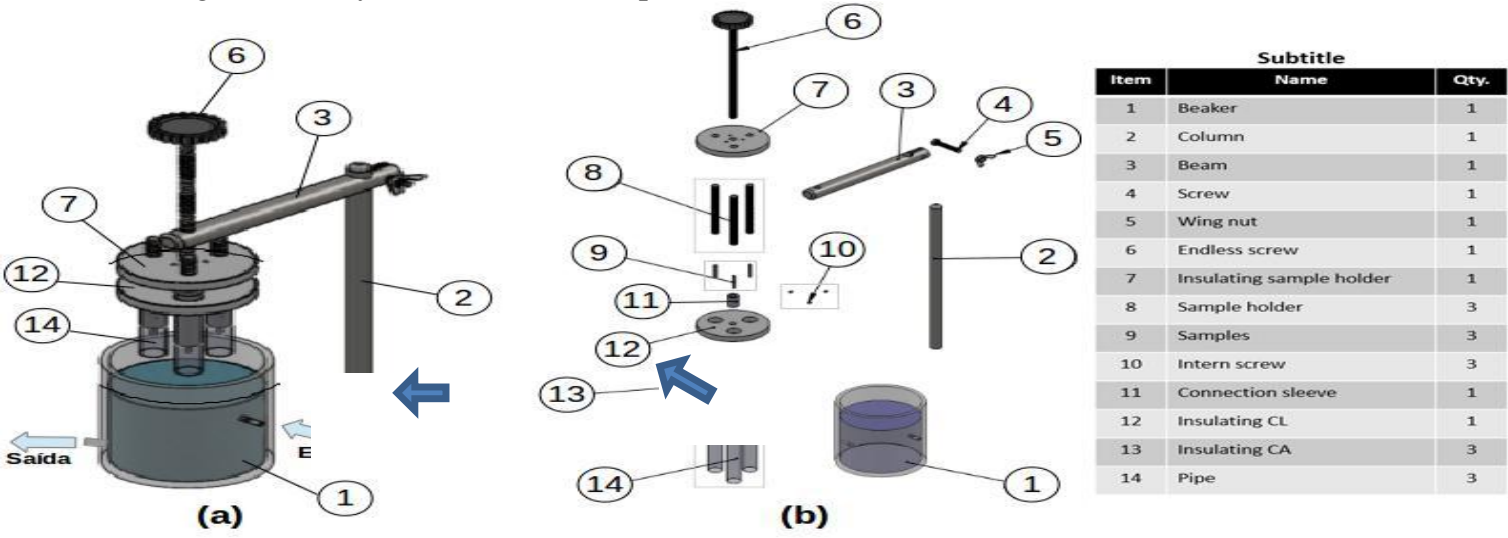

Fig 2:-3D drawing of the PEO equipment (a) mounted isometric view and (b) schematic representation of exploded view.

\footnotetext{
${ }^{1}$ Trademark of Dassault Systèmes SolidWorks Corporation (DS SolidWorks)
} 
Fig 3 shows the modeling of the assembled equipment with a longitudinal sectional view (Section A-A) and detail. Fig 3 (a) shows the detailed view that evidences the inner region between the pipe (14) and the sample (9) representing the coating chamber, where the phenomenon of the ceramic coating on the metal happens. The pipe (14) and the sample (9) represent the electrodes of the coating chamber that correspond to the anode and cathode, respectively. The sample (9) was fixed on the sample holder (8) and, therefore, it has the same polarity. In order to avoid physical contact and change of the distance between the electrodes, a CA insulating was used (13). Thus, the titanium sample (9) was positioned concentric to the pipe (14), distance of $2 \mathrm{~mm}$.

Fig 4 shows the exploded view of the PEO coating reactor with its 5 components. First, the sample holder (8) was assembled in the insulating CA (13) since the sample holder (8) has the shape of a screw with M8 nut and the insulating CA (13) has an internal M8 nut. A threading system was used to assemble these components and positioning adjustment in a practical, fast and precise way. Then, the titanium sample (9) was positioned in the sample holder (8) and fixed (making pressure contact) through the internal screw (10). Finally, this system, previously assembled, was fixed on the pipe (14). Between the external surface in the insulating CA (13) and the inner surface of the pipe (14), there was a slack of 1 tenth millimeter to facilitate the assembly and disassembly between the treatments.
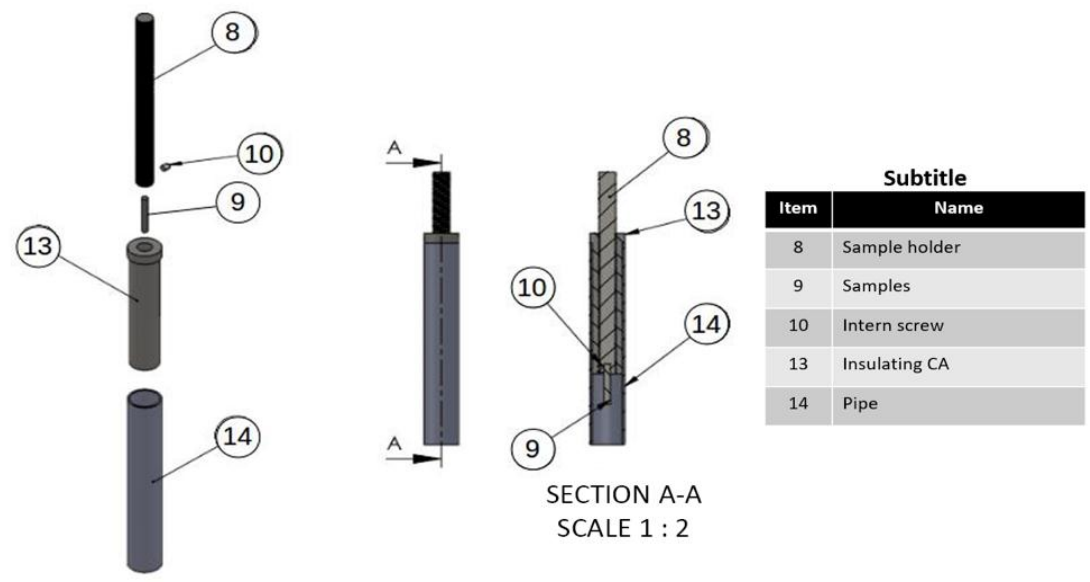

Fig 3:-Modeling of the assembled equipment with a longitudinal sectional view (Section A-A) and detail that evidences the internal region of the mounted reactor.

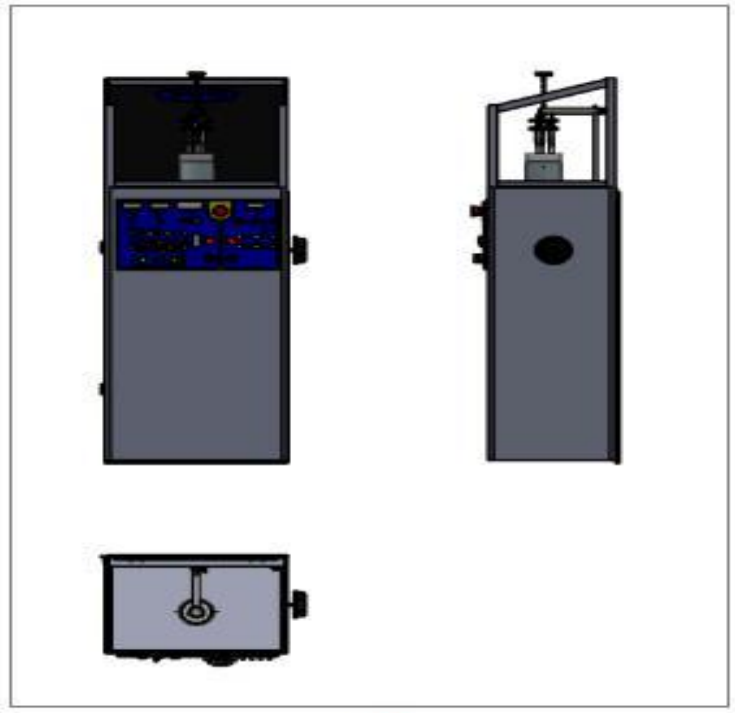

a)

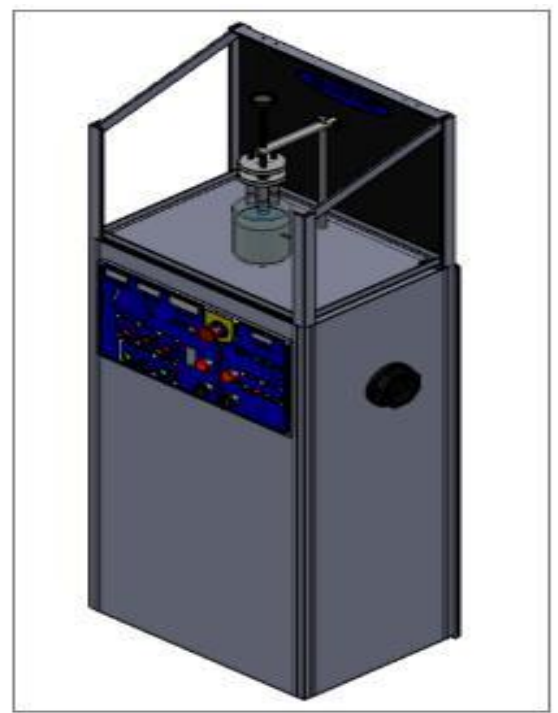

b)

Fig 4:-Isometric view of the PEO reactor assembled (a) View of the reactor in 3D plane (b). 


\section{Electric source}

The electrical source used for this work had a maximum power of $1.3 \mathrm{~kW}$. This source was conFigd to generate alternating current (AC) and current by a variac that controls a continuous voltage range from 0 to $700 \mathrm{~V} \mathrm{AC}$. However, a parallel circuit conFigd with the complete Wheatstone bridge with four (4) diodes ( 1N5808), to rectify the signal, becoming continuous current (CC). This way, the PEO reactor has a CC and a CA output.

\section{Sample preparation}

For the preparation, it was used 18 samples of Ti-cp type II with $3 \mathrm{~mm}$ diameter and $25 \mathrm{~mm}$ length. The samples were cleaned with a dilute mixture of hydrofluoric (HF) and nitric (HN) acids, $5 \mathrm{ml}$ of HF into $100 \mathrm{ml}$ of deionized water and $5 \mathrm{ml}$ of $\mathrm{HN} \mathrm{O}_{3}$ into $100 \mathrm{ml}$ of distilled water, with volume fractions of $10 \%$ and $40 \%$, respectively, during 30 seconds in order to remove the oxide layer and contaminants from the surface. The samples were cleaned in ultrasound bath (PlanaTC-CBU 100/3L) with acetone and distilled water for 10 minutes, respectively. After washing, the substrates were dried with the aid of a thermal blower (Taiff Turbo 6000), ensuring removal of impurities and absence of superficial residues that could contaminate the electrolytic solution.

\section{Preparation of electrolytic solution}

The electrolytic solution used in this work was composed by $10 \mathrm{~g} / \mathrm{L}$ of sodium phosphate tribasic P.A. (FST, N a3P $\mathrm{O} 4 \Delta 12 \mathrm{H} 2 \mathrm{O}$ ) and $2 \mathrm{~g} / \mathrm{L}$ of potassium hydroxide $(\mathrm{KOH})$ in 1 liter of distilled water. It was added $3 \mathrm{~g} / \mathrm{L}$ of Tris hydroxymethyl Aminomethane P.A. (C4H11N O3) as additive to the electrolyte, since studies have shown that the electrolytic solution containing these elements enables an adherent and osseointegration favorable coating for Ti (HARIPRASAD et al., 2016). Table 1 shows the chemical composition, $\mathrm{pH}$ and conductivity (k) of the electrolyte used in this work.

Table 1:-Chemical composition, $\mathrm{pH}$ and conductivity of the electrolyte.

\begin{tabular}{|c|c|c|}
\hline Elecrolyte composition & $\mathrm{pH}$ & $\mathrm{K}(\mathrm{mS} / \mathrm{cm})$ \\
\hline $10(\mathrm{~g} / \mathrm{L}) \mathrm{N} \mathrm{a}_{3} \mathrm{P} \mathrm{O}_{4} 12 \mathrm{H}_{2} \mathrm{O}+2(\mathrm{~g} / \mathrm{L}) \mathrm{KOH}+3(\mathrm{~g} / \mathrm{L}) \mathrm{C}_{4} \mathrm{H}_{11} \mathrm{~N} \mathrm{O}_{3}$ & 12.16 & 12.45 \\
\hline
\end{tabular}

The substances were weighed on an analytical scale (Chimis R Q-500L210C) and, subsequently, they were added into a $600 \mathrm{ml}$ beaker and dissolved in $400 \mathrm{ml}$ of distilled water. Then, the solution was placed in a volumetric flask of 1 liter, completing the volume with distilled water and mixing for 1 minute.

For each treated sample, $600 \mathrm{ml}$ of solution was used and, in order to ensure that the conditions of equal treatment were maintained, the electrolytic solution was replaced after each experiment. The $\mathrm{pH}$ and conductivity of these electrolyte solutions were measured by a Multimeter PCTestr 35 (Oakton Instruments, Singapore) and ECTestr11 + (Oakton Instruments, Singapore) multimeter conductivity meter at room temperature, respectively.

\section{Apparatus and Experimental parameters}

Fig 5 represents the experimental apparatus design, with the representation of only one deposition reactor (representative), once that this work prsents 3 reactors, as shown in Fig 6. Thus, the experimental apparatus has three PEO coating reactors, magnetic agitator, electrolyte recirculation system, flow control valve and digital thermocouple Tic 17RGTI $\left(-50\right.$ to $\left.105^{\circ} \mathrm{C}\right)$. The titanium samples and the stainless steel pipe were used as anode and catode, respectively. The magnetic stirrer was used to maintain the uniformity of the electrolyte. The recirculation system was used to minimise any thermally-driven growth processes. 


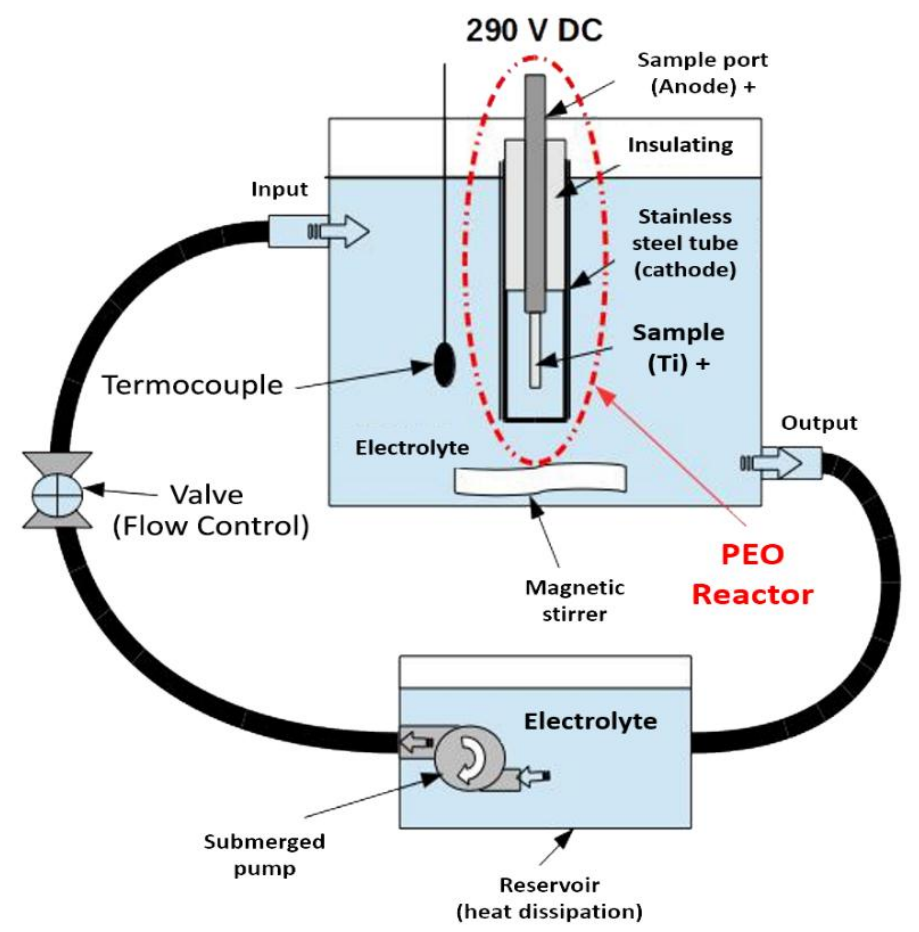

Fig 5:-Experimental apparatus.

Fig 6 represents the experimental conditions used in this study. A voltage of $290 \mathrm{~V}$, continuous current (CC) was submitted to the treatment time of $1(\mathrm{t} 1), 8(\mathrm{t} 2)$ and $16(\mathrm{t} 3)$ minutes. The voltage of $290 \mathrm{~V} \mathrm{CC}$ was chosen because it is the limit voltage of the electrical power source for the PEO equipment. For each time presented above, the positions P1, P2 and P3 were used. Fig 6 (a) shows the t1 time, highlighted by the rectangle with a red dashed line, connected with positions P1, P2 and P3. In the first treatment, the time of one minute (t1) and position P1, therefore only R1 reactor was used to coat a sample. The green color of the reactor R1, at position P1, indicates that it is active and the reactors R2 and R3 in black are deactivated. Next, another treatment with the same time (t1) was performed at the P2 position, which activated reactors R1 and R2 and, therefore, two samples were coated. Finally, t1 was used for treatment at $\mathrm{P} 3$ position, where three simultaneous coatings were performed in the reactors R1, R2 and R3. For t2 (Fig 6 (b)) and t3 (Fig 6 (c)), the same procedures were performed.

Thus, for each time adopted in this work, three positions were performed using 6 samples. For the three times, 18 samples were used. The electrical voltage, current and temperature were monitored and recorded every minute. 


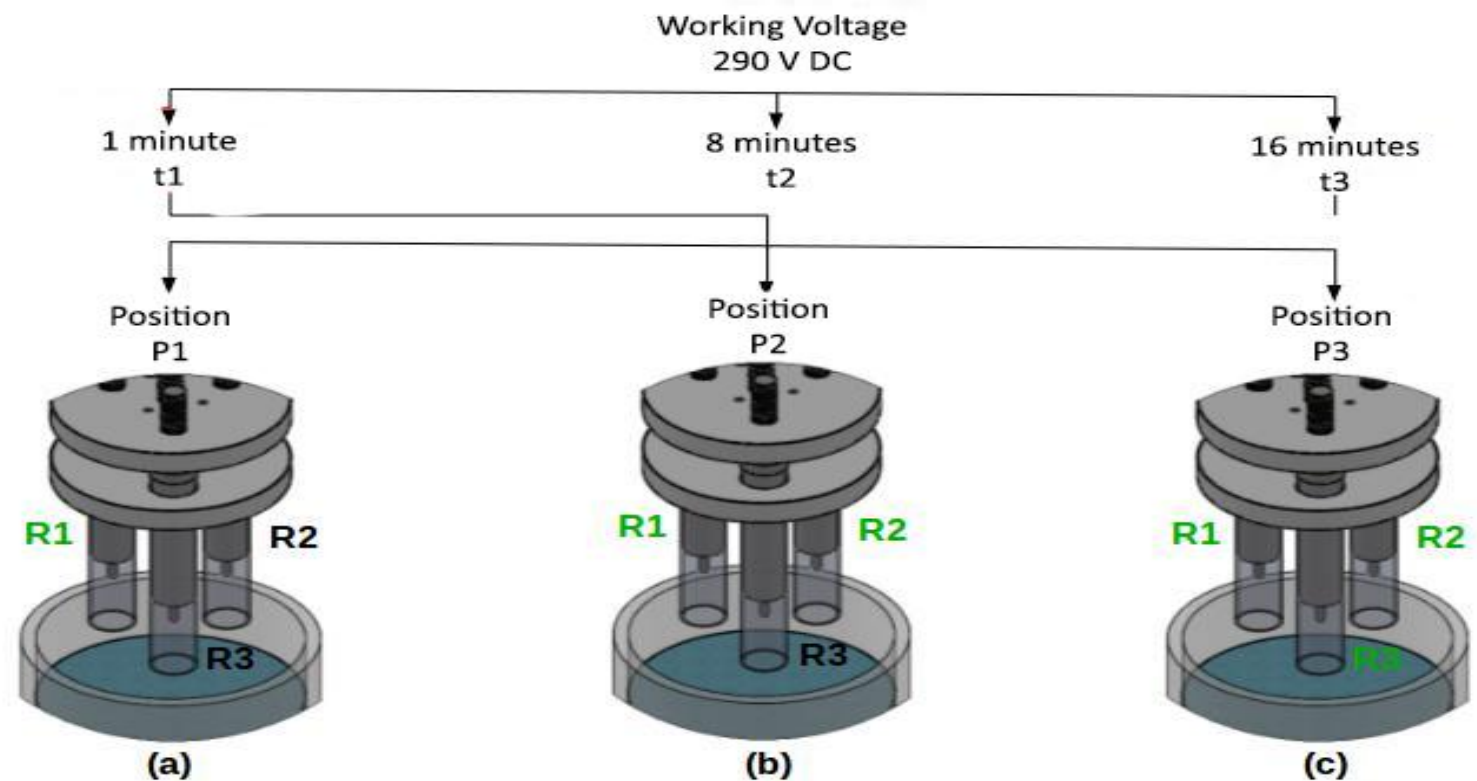

Fig 6:-Combination of experimental conditions for the PEO treatments in times t1 (1 minute), t 2 (8 minutes) and t3 (16 minutes) in positions P1 (a), P2 (b) and P3 (c).

\section{Results And Discussion:- \\ PEO reactor operation}

Fig 7 a) presents the 3D CAD modeling of the PEO reactor and Fig 7 b) presents the photograph of the manufactured equipment. The PEO reactor layout favored the control and monitoring of the work parameters. Thus, it was possible to control and monitor the electrical source (CC or $\mathrm{AC})$, water pump, magnetic agitator, the three deposition chambers and temperature of the reservoir containing the electrolytic. Through the panel, it was possible to monitor voltage and current signals (CC and $\mathrm{AC}$ ) and temperature, in addition to the possibility of preprogramming the treatment time in a digital form. Moreover, it was possible to control and monitor electrical parameters of the process. The PEO reactor presented a protection system of excessive load and grounding. The reactor coated titanium rods with good performance and did not present leakage of current in undue places, showing that the scaling and electrical installation were adequate. This robustness enabled the control of all parameters in an ergonomic, practical and safe way.
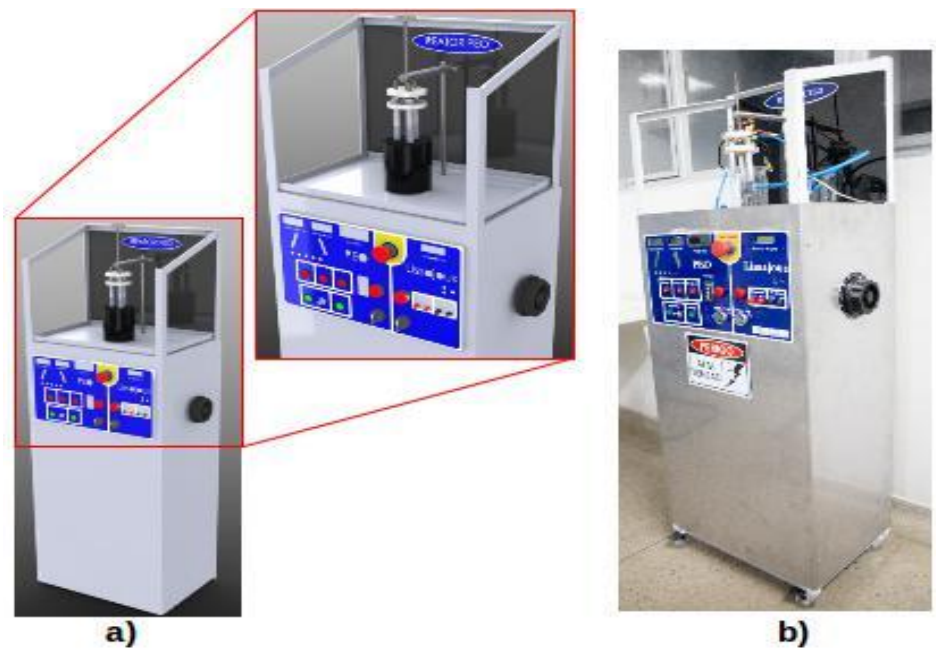

b)

Fig 7:-3D CAD modeling a) and photograph of the manufactured PEO Reactor b). 
Fig 8 shows the titanium samples fixed in the sample holder. In addition, Fig 8 a) shows three fixed samples in the equipment and Fig 8 b) represents an increase, evidencing the headless internal hexagonal screw (sample fixer) and fixed titanium sample in the stainless steel sample port.

The work of (YEROKHIN et al., 2003) proposed that the initiation of discharge via PEO should be by emitting electrons from the electrolytic interface with the gaseous phase, instead of the development of ionization by impact on the growing oxide film. This process causes temperature peaks that melt the materials present in the medium and that, when they are cooled quickly by the electrolyte, it causes the solidification of molten oxide on the substrate surface. Due to the repeated melting and solidification process, induced by discharges, the temperature would allow the crystallization and transformations of the titanium oxide $\left(\mathrm{T} \mathrm{iO}_{2}\right)$ phase from Anatase to Rutile (YEUNG, 2016).

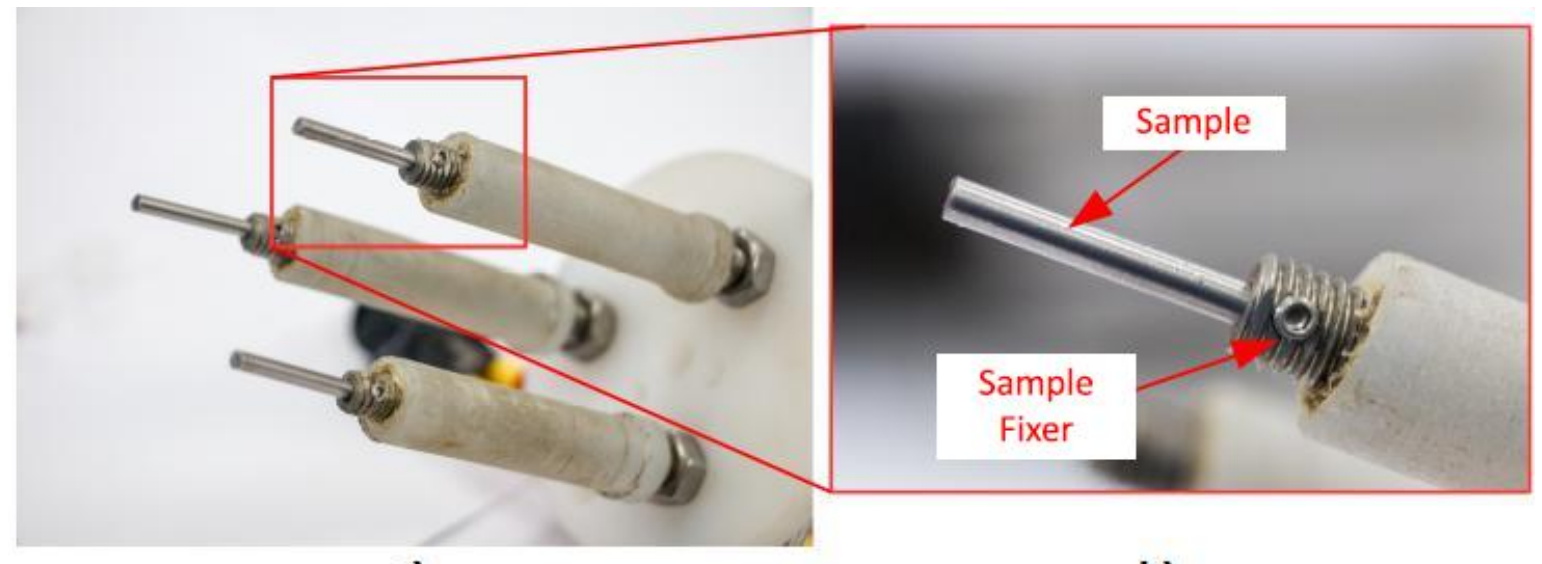

a)

b)

Fig 8:-Titanium samples fixed on the sample holder a) and enlarged image of increased specimen fixation by screw in the sample holder b).

Fig 9 shows the treatment chamber where the ceramic coating process occurs on the titanium surface. This initial configuration did not present lateral spaces for exhaust gases produced in the PEO process, formation of gas $\left(\mathrm{O}_{2}\right.$ and $\mathrm{H}_{2}$ ) within the treatment chamber (TEH et al., 2003) (PARFENOV et al., 2015). Thus, in the course of the treatment, the gas formed and confined inside the chamber, increases the internal pressure until it overcomes the hydrostatic pressure of the electrolytic, generating "explosions" that caused vibrations that preclude the treatment. In order to solve this problem, four longitudinal sections of $2 \mathrm{~mm}$ of thickness and $25 \mathrm{~mm}$ in length were performed in each wall of the stainless steel pipes (cathode), as can be seen in Fig 9 b). These lateral cuts functioned as outlets for the gases formed during the treatment process.

At the beginning of the process, the high current density on the surface of the working electrode promotes an intensive evaporation of the electrolytic solution. This process causes the formation of gas and oxides in the substrate interface (sample). In the region of gas formation, there is a decrease in dielectric strengh, for the difference of applied potential, promoting a luminescent discharge known as plasma. These phenomena distinguish electrolytic oxidation by plasma from other electrolytic processes, justifying the use of the term "plasma". Due to the polarization effect on the anode forms itself a stationary oxide film. By achieving the disruption of the dielectric barrier in this thin film, the micro discharges appear on its surface (PARFENOV et al., 2015). Thus, the conductivity and semiconductor properties of the film directly influence the characteristics of the discharge (GORDIENKO et al., 2009). 


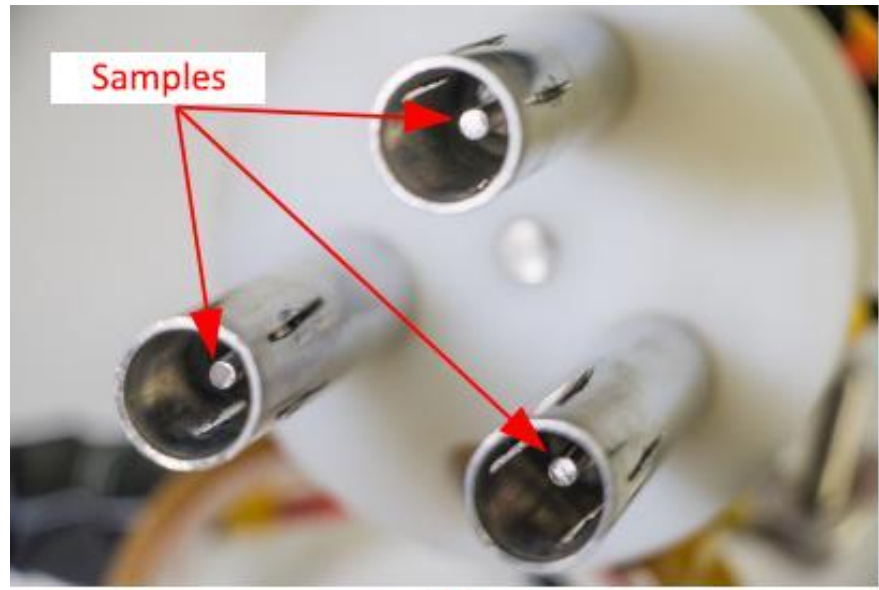

a)

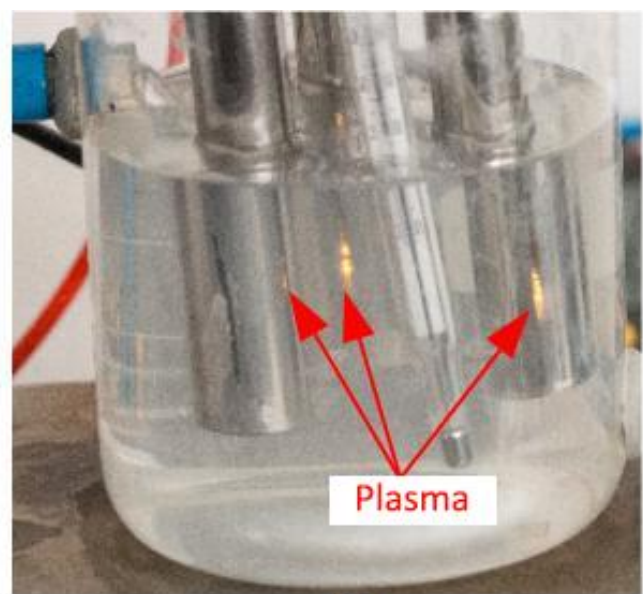

b)

Fig 9:-Samples positioning in the reactors a). Lateral view of the immersed electrodes, highlighting the cracks for gas exhaustion $b$ ).

After these interventions the experiments were stable and the coatings presented high quality and uniformity, as can be seen in Fig 10, which presents the sample without (lower sample) and with treatment (upper sample).

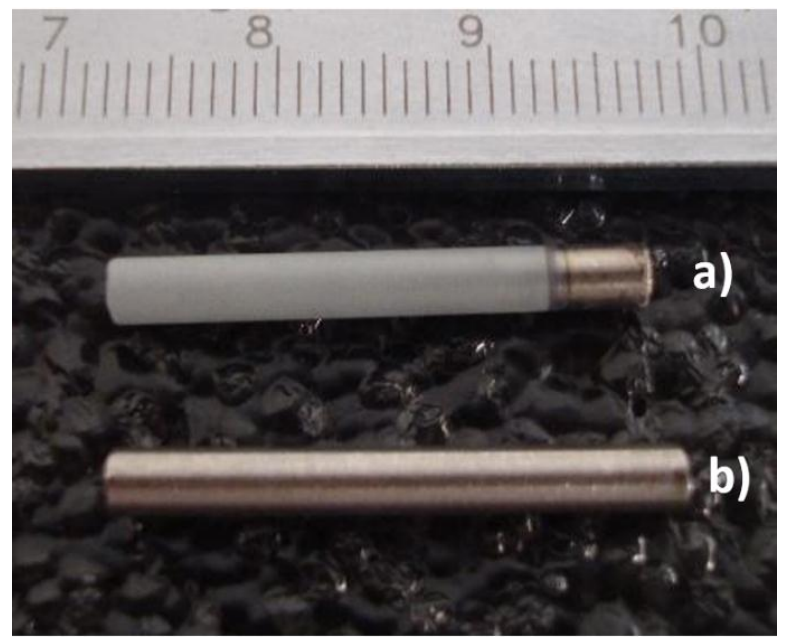

Fig 10: Sample with a) superficial treatment by PEO and B) without treatment.

\section{Topography}

Fig 11 a), b) and c) present the SEM images of the treated surfaces for 1 minute a), 8 minutes b) and 16 minutes c), respectively. All coatings exhibit a common characteristic of a PEO process, presenting a porous structure in the outer layer. However, the surfaces of the PEO coatings were distinguished by pore distribution and size of the main pores (HARIPRASAD et al., 2016). With the addition of TRIS, it was possible to promote the increase in the electrolyte conductivity and, in this way, decreased the dielectric resistance between the poles and, consequently, the density of discharges was increased to the same voltage value provided that favors discharges resulting in higher porosity (HARIPRASAD et al., 2016).

The surface morphology of the t1P3R1 sample presented micropores and isolated pores evenly distributed on the surface. Among all coatings, the t1P3R1 sample had relatively lower porosity and higher density that is directly related to the treatment time. The surfaces reveal numerous pore with micrometric sizes, which tend to increase in size with increase of treatment time (CHENG et al., 2013). For the 1-minute treatment, Fig 11 a) presented a surface with rounded shapes pores between "smooth" regions. The pores on the surface of the film were filled by the electrolyte, favoring the passage of current. And during this phase, $\mathrm{O}_{2}$ was formed in the interface between the electrolyte and the coating, and thus, being possible answer for the round pores (KUROMOTO; SIMON SOARES, 
2007). The presence of rounded symmetrical pores and well distributed to the condition applied to the t1P3R1 sample (Fig 11) can also be attributed to the shortest time stage of treatment (GOWTHAM; ARUNNELLAIAPPAN; RAMESHBABU, 2016).

Initially, the natural layer of $\mathrm{TiO}_{2}$ grows and join together, forming a smooth region. Then, some areas develop cracks and become porous. With the increase of the electrical tension values, the film separates locally from the regions of the original layer and grows a new layer that it is developed simultaneously and parallel, occupying more surface as the treatment time increases (BAYATI; MOSHFEGH; GOLESTANI-FARD, 2010). Therefore, the resulting film constitutes the combination of flat and porous regions. When the anodic strain presents a high potential difference, it causes the migration of $\mathrm{O}_{2}$ ions to the metal/coating interface and migration of $\mathrm{Ti}^{4+}$ ions to the coating/electrolyte interface, thus forming the $\mathrm{TiO}_{2}$ film (LI et al., 2017a). The anionic components in the electrolyte are involved in electrochemical reactions on the anodic surface and influence the morphology and composition of the oxide coatings.

The distribution of plasma discharge or pore channels provided a passage to $\mathrm{PO}_{4}{ }^{3-}, \mathrm{HCO}_{3}{ }^{-}, \mathrm{HPO}_{4}{ }^{-}$and $\mathrm{NO}_{2}{ }^{-}$for a fast entrance in a PEO coating. Previous researches (VENKATESWARLU et al., 2012) (K et al., 2013) (HARIPRASAD et al., 2016) show that the ionic species entered and influenced the surface morphology of the PEO coatings. According to $\mathrm{K}$ et al. (2013), the characteristics of the pores depend heavily on the electrolytic conductivity, rupture tension of the layer and tension of film formation.

There are many reactions occurring during the process and most relevant reactions that participate in the growth of the film are those that produce $\mathrm{O}_{2}$ and $\mathrm{TiO}_{2}$ (SU; ZHOU, 2008) (CHENG et al., 2017). The work of Gowtham, Arunnellaiappan and Rameshbabu (2016) argued that pore formation in PEO coatings is the result of dielectric breaking of oxide films from electrical tensions far superior to the conventional anodizing process.

The t2P3R1 sample, Fig $11 \mathrm{~b}$ ), had wider spherical and irregular pores from $2 \mu \mathrm{m}$ to $6.5 \mu \mathrm{m}$, respectively, besides smaller pores of $0.8 \mu \mathrm{m}$.

The t3P3R1 sample, Fig $11 \mathrm{c}$ ), presented wide and irregular pores that vary up to $12 \mu \mathrm{m}$ in length. Smaller pores were found in these irregular pores. The researchers (DEHNAVI et al., 2015) suggested that the luminescent discharges of the high-intensity PEO process are generated when operated at high service. The pulses in time are longer for the t3P3R1 sample, and consequently, implying the presence of high intensity discharges and generation of higher energy per pulse. The work of (DUNLEAVY et al., 2009) reported that individual sparks have a natural life and there is the possibility that these shorter discharges occur in cascades. In addition, the spatial density of sparks can also be lower for the sample t3P3R1 (DEHNAVI et al., 2013). The wider pores and the highest porosity can, thus, be attributed to the low operation that creates a smaller number of live sparks, i.e. a long cascade of sparks and higher energy per pulse.

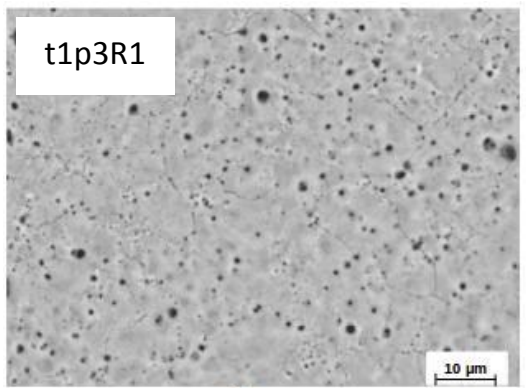

a)

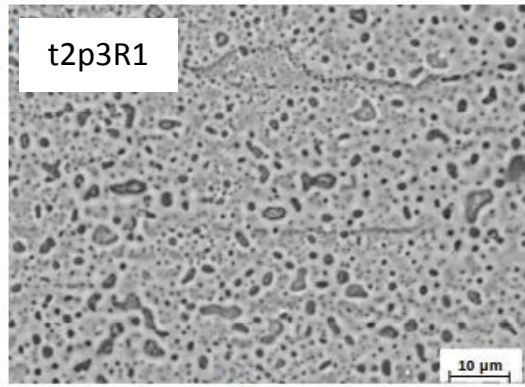

b)

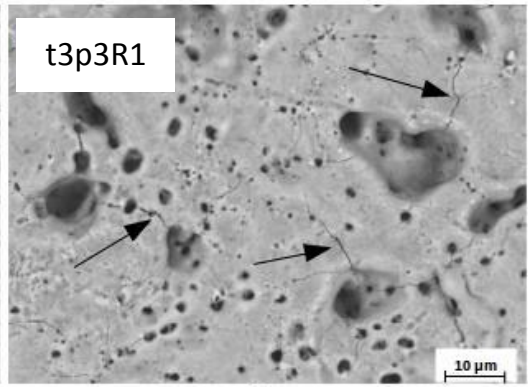

c)

Fig 11:-SEM of the surface of samples treated by PEO with an increase of 2000x: at position 3 (P3) and reactor 1 (R1) for treatments of 1 minute a); 8 minutes b) and 16 minutes c).

\section{Analysis of the layer thickness area by optical microscopy}

Fig 12 shows cross section images of the studied samples. The first line of Fig 12 represents the samples: t1P1, t2P1, and $\mathrm{t} 3 \mathrm{P} 1$. The second line of Fig 12 represents the samples: t1P2, t2P2, and t3P2. And finally, the third line in Fig 12 represents the samples: $\mathrm{t} 3 \mathrm{P} 3, \mathrm{t} 3 \mathrm{P} 3$, and $\mathrm{t} 3 \mathrm{P} 3$. The $\mathrm{OM}$ images suggest that all coatings have good bonding with 
the substrate, since no defect, such as cracks, pores or delamination, was apparent in the region of the titanium and coating interface (CHENG et al., 2013) (RAFIEERAD et al., 2015) (WANG et al., 2015). These results are in accordance with the literature (LI et al., 2017a) (Hariprasad et al., 2016), where it was stated that the coatings made in titanium with phosphate as constituent substance of the electrolyte has an excellent adhesion and thermal shock tests, essential features for an implant.

A visual analysis of the coating layer thickness for the first line of Fig 12 (t1P1, t2P1 and t3P1), it is clear that there was a difference in the thickness between t1P1 and t2P1. However, this variation does not occur between the conditions t2P1 and t3P1 which has similar thicknesses. This behavior was achieved even with the time variation being the same between (t1P1 and $\mathrm{t} 2 \mathrm{P} 1)$ and $(\mathrm{t} 2 \mathrm{P} 1$ and $\mathrm{t} 3 \mathrm{P} 1)$ that are 8 minutes. Thus, it can be stated that the growth rate between times ( $\mathrm{t} 1$ and $\mathrm{t} 2)$ and ( $\mathrm{t} 2$ and $\mathrm{t} 3)$ are different. This behavior was repeated for the three positions P1, P2 and P3. However, the analysis of the coating layer area revealed that there is a variation that should be considered. For lines 2 (t1P2, t2P2 and t3P2) and $3(\mathrm{t} 1 \mathrm{P} 3, \mathrm{t} 2 \mathrm{P} 3$ and $\mathrm{t} 3 \mathrm{P} 3)$, the same behavioral tendency was verified. In addition, one can observe that although there was a good adhesion, there were variations in the thickness.

a)
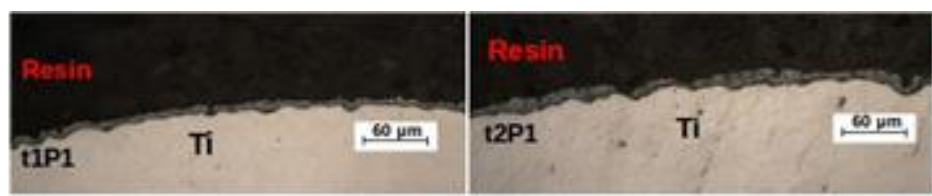

b)
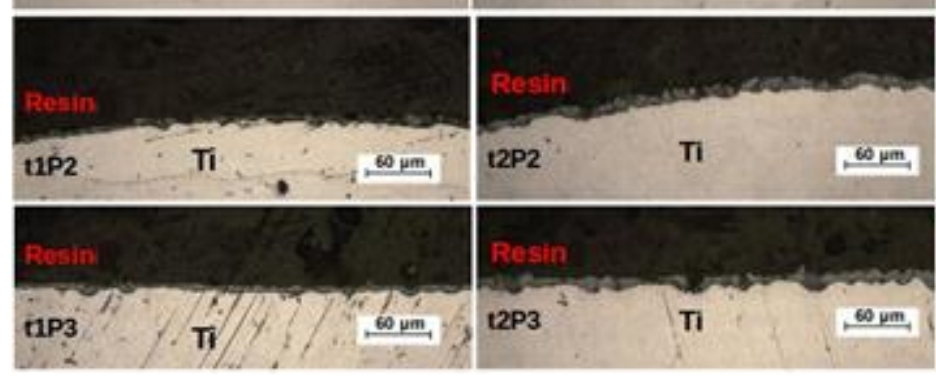

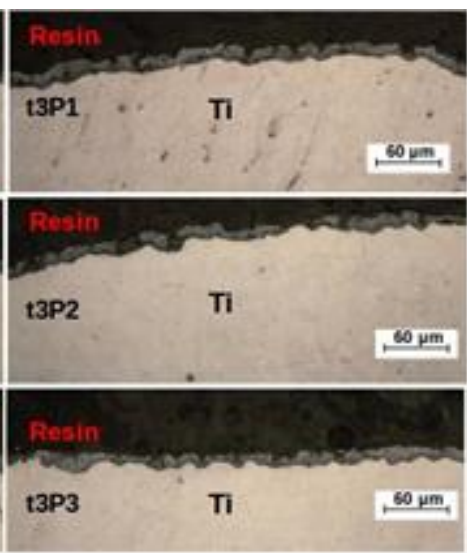

Fig 12:-Optical microscopy (OM) of cross section cutting of samples: t1P1, t2P1 and t3P1 a); t1P2, t2P2 and t3P2 b) and t1P3, t2P3 and t3P3 c) with 500x enlargement.

The results show that there was a growth rate for the layer thickness between the times 1 and 8 minutes, when a thickness "stagnation" was reached. The results revealed by the SEM topography, wettability and roughness suggest that the energy consumed between the time of 8 and 16 minutes are intended to promote the topographic modification of the coating. The SEM topographic image for samples $\mathrm{t} 1, \mathrm{t} 2$ and $\mathrm{t} 3$ revealed a clear modification between the distribution and pore shape. The increase in time caused alterations greatly in the size and distribution of the pores. In addition, the results of wettability and roughness sustain this theory. Therefore, the results lead to the statement that the coating formation in this work was divided in two main parts. In the first, the energy consumed in the process was used for the coating growth. In the second, the energy was intended for the topographic alteration of the coating. This change of behavior can be justified by the authors Cheng et al. (2013) who affirm that the modification of the surface morphology by the PEO process, may be a result of a change in the discharges nature. The work of Li et al. (2017a) have also shown that phosphate electrolytes produce PEO coatings, mainly by the oxidation of the titanium substrate, leading to more internal growth. The predominance of internal growth promotes a compact coating structure and high adhesion, however the coatings show low growth rate. 


\section{Energy dispersive spectroscopy (EDS)}

Fig 13 shows the atomic weight quantity of the chemical elements for the t1P3R2 samples along with the image of the sample location where the quantification was performed.

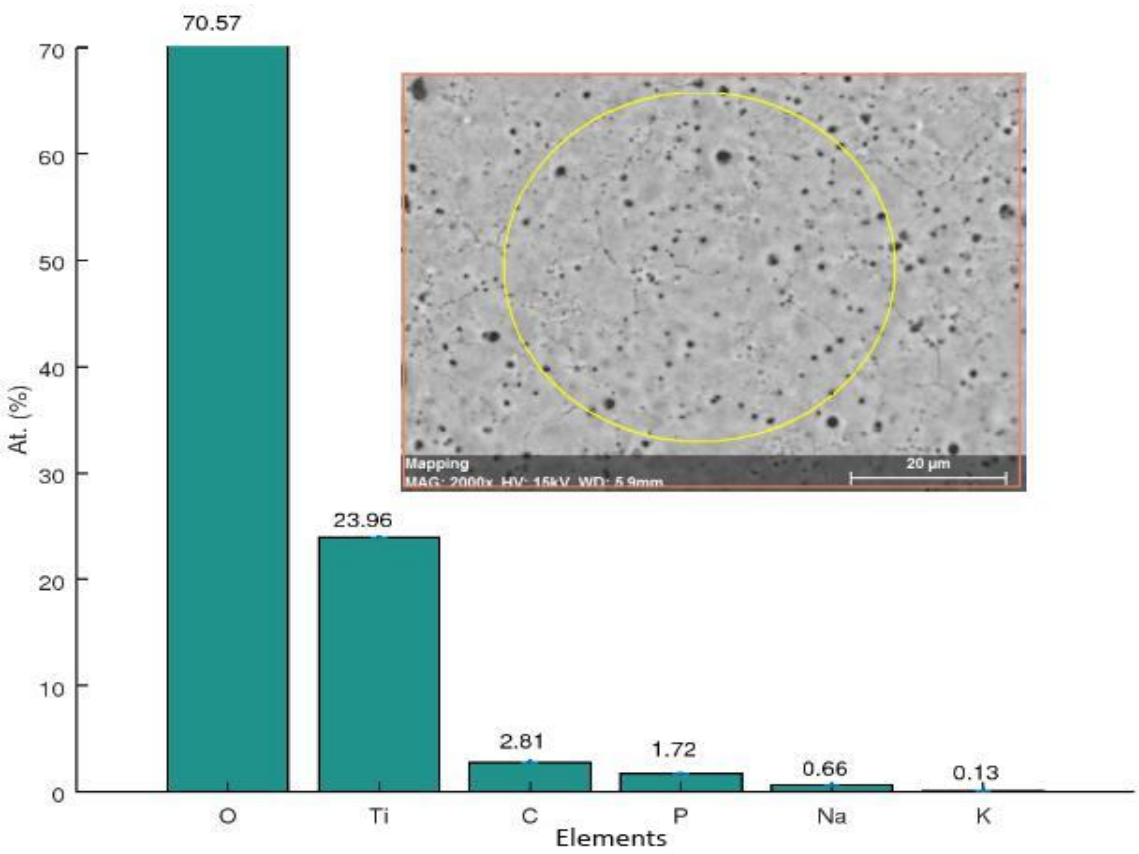

Fig 13:-Energy Dispersive Spectroscopy showing the chemical elements found ( $\mathrm{O}, \mathrm{Ti}, \mathrm{C}, \mathrm{P}, \mathrm{Na}$ and $\mathrm{K})$ in the t1P3R2 sample, due to its representativeness.

Fig 14 shows the atomic weight quantity of the chemical elements of the t2P3R2 samples together with the image of the sample location where the quantification was performed.

The EDS spectra indicated that the titanium coatings were composed by oxygen $(\mathrm{O})$, titanium (Ti), carbon (C), phosphorus $(\mathrm{P})$, sodium $(\mathrm{Na})$ and potassium $(\mathrm{K})$, elements that compose the electrodes and electrolyte used in the PEO process. The elements with higher concentration were oxygen and titanium, therefore, this result shows a great viability for the formation of $\mathrm{TiO}_{2}$ oxides. The quantity of the elements presented by EDS is highly associated to the electrolyte composition, the higher the concentration of the material, the greater the quantity of material added in the coating (RENDÓN et al., 2015). Anionic species, such as $\mathrm{PO}_{4}{ }^{3-}, \mathrm{HCO}_{3}{ }^{-}, \mathrm{HPO}_{4}{ }^{-}$and $\mathrm{NO}_{2}{ }^{-}$, derived from the electrolyte that could be incorporated into the film during the PEO process (HARIPRASAD et al., 2016). The EDS analysis revealed the presence of phosphorus in the PEO coatings t1P3R2, t2P3R2 and t3P3R2 at an atomic percentage of $1.72 \%, 6.49 \%$ and $2.5 \%$, respectively, Table 2 . However, the incorporation of phosphorus depends on the conductivity of the electrolyte and the tension of the respective PEO process (K et al., 2013). It is known that the presence of phosphorus in PEO coatings can improve the bioactivity of titanium implants (KHAN et al., 2014).

Also, it must be highlighted that the content of the titanium (Ti) is much higher than the phosphorus (P) in the coating, suggesting that the PEO coating growth is mainly from the oxidation of Ti substrate on the phosphate electrolyte (LI et al., 2017a). 


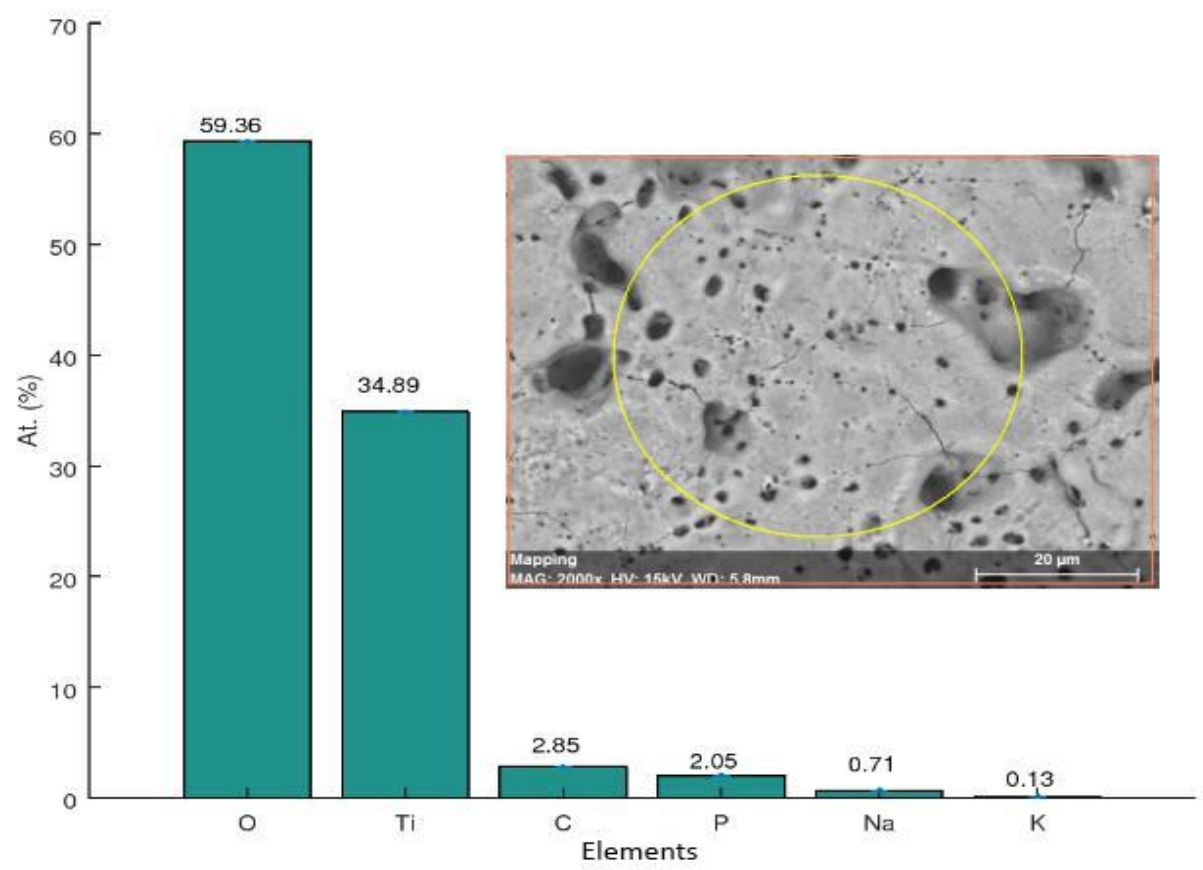

Fig 14:-Analysis of energy dispersive spectroscopy showing the chemical elements found $(\mathrm{O}, \mathrm{Ti}, \mathrm{C}, \mathrm{P}, \mathrm{Na}$ and $\mathrm{K})$ in the t3P3R2 sample, due to its representativeness.

Table 2:-EDS of superficial chemical composition for the samples treated by PEO.

\begin{tabular}{|c|c|c|c|c|c|c|}
\hline \multicolumn{7}{|c|}{ Atomic content in porcentage (\%) } \\
\hline Sample & $\mathbf{O}$ & Ti & $\mathbf{C}$ & $\mathbf{P}$ & $\mathbf{N a}$ & K \\
\hline t1P3R2 & 70.57 & 23.96 & 2.81 & 1.72 & 0.66 & 0.13 \\
\hline t2P3R2 & 52.47 & 35.75 & 3.23 & 6.49 & 0.71 & 0.21 \\
\hline t3P3R2 & 59.36 & 34.89 & 2.85 & 2.05 & 0.71 & 0.13 \\
\hline
\end{tabular}

The elemental composition of the surface treated with PEO, analyzed by EDS, shows the incorporation of Na, P and $\mathrm{K}$ species in a smaller quantity in titanium oxide coatings as reported in Table 2 . The SEM analysis showed that the samples presented the typical porous morphology of the PEO coating (GOWTHAM; ARUNNELLAIAPPAN; RAMESHBABU, 2016) (HARIPRASAD et al., 2016). A closer look shows that there are morphology differences in the samples. These differences are due to the presence or absence, in varying degrees, of three characteristics, namely a portion of stain, smaller spherical pores and larger irregular pores. The differences in the characteristics formed are the result of different treatment conditions and difference in the characteristics of the spark and the behavior of the coating growth (GOWTHAM; ARUNNELLAIAPPAN; RAMESHBABU, 2016).

\section{Wetabillity}

According to Gowtham, Arunnellaiappan and Rameshbabu (2016), a hydrophilic surface is a required factor in order to obtain favorable bioactivity. Therefore, Fig 15 shows the influence of the contact angle with time for the three positions used in this work. The results showed that the uncoated sample obtained a contact angle of $48.3^{\circ} \pm 3^{\circ}$. While, Fig 15 a) presents the influence of position 1 (P1) with the treatment times was verified. The values of $34.7^{\circ}$, $5.3^{\circ}, 18.3 \pm 0.5^{\circ}$ and $9.0 \pm 1.2^{\circ}$, were obtained for the samples t1P1R1, t2P1R1 and t3P1R1, respectively. One can observe a linear decrease of the contact angle with the treatment time. Fig $15 \mathrm{~b}$ ), show the influence of position 2 $(\mathrm{P} 2)$ with the treatment times was verified. Fig $15 \mathrm{~b}$ ) showed the values of $30.7 \pm 3.8^{\circ}, 18.5 \pm 2.2^{\circ}$ and $10.9 \pm 2.0^{\circ}$, for the samples t1P2R1, t2P2R1 and t3P2R1, respectively. Finally, Fig $15 \mathrm{c}$ ) presents the influence of position 3 (P3) was verified with the treatment times, obtaining values of $29,8 \pm 3,4^{\circ}, 20,3 \pm 4,3^{\circ}$ and $12,5 \pm 1,0^{\circ}$. The results presented in Fig 15 a), b) and c) showed a tendency, practically, linear of the contact angle according to the treatment time. It was evident that only the treatment time was determinatively to interfere in the responses of the contact angle, for this analysis in question. For all conditions, it was possible to obtain the reduction of the contact angle in relation to the untreated sample $(\mathrm{P})$. 

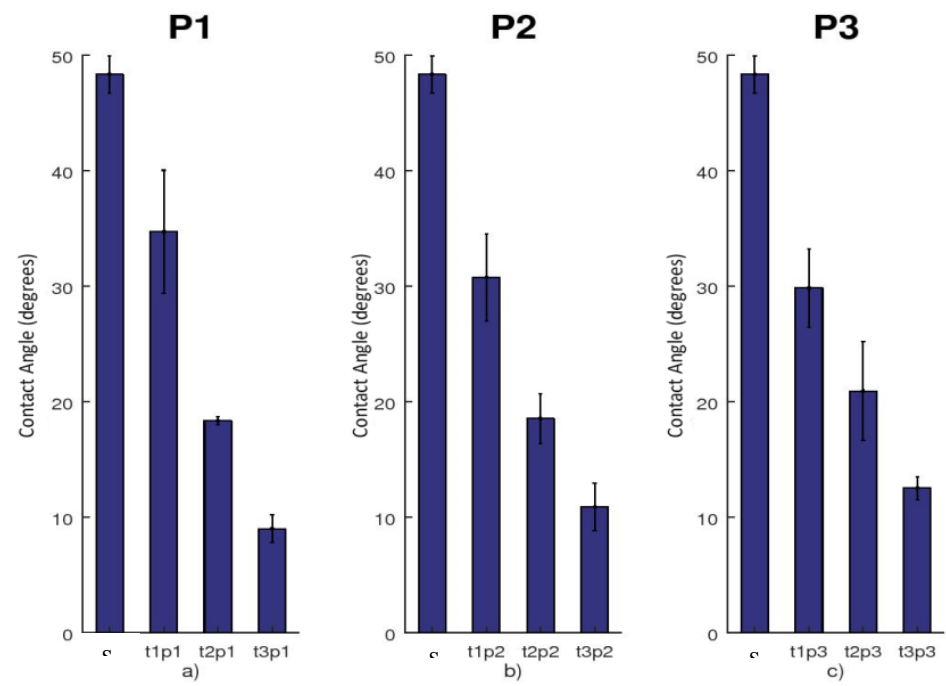

Fig 15:-Wettability comparison for condition 1 (t1), 8 (t2) and 16 (t3) minutes of treatment for position P1 a), P2 a) and P3 c).

Fig 16 a), b) and c) present a comparative analysis between positions P1, P2 and P3 for the time of 1 minute (t1) a), 8 minutes (t2) a) and 16 minutes (t3) c). Considering the deviation without treatment, it can be stated that there was no change in the treatment contact angle and, in this way, it is perceived that the use of multiple reactors simultaneously does not affect the responses of the contact angle for this case studied.

In this way, all the conditions obtained results from smaller contact angles when compared to the reference sample. These results indicate that the PEO coatings produce hydrophilic surfaces. This can be explained by the increase in porosity with the increase of treatment time. Fig 17 performed on the surface of a sample treated for 8 minutes shows the high porosity and interconnection of the pores, highlighted by the arrows, justifying the high wettability and rapid absorption of water on the samples surfaces. The work of (WHEELER et al., 2010) highlighted that phosphate-containing electrolyte coating has a higher degree of porosity on its surface. This characteristic can be seen in Fig 17.
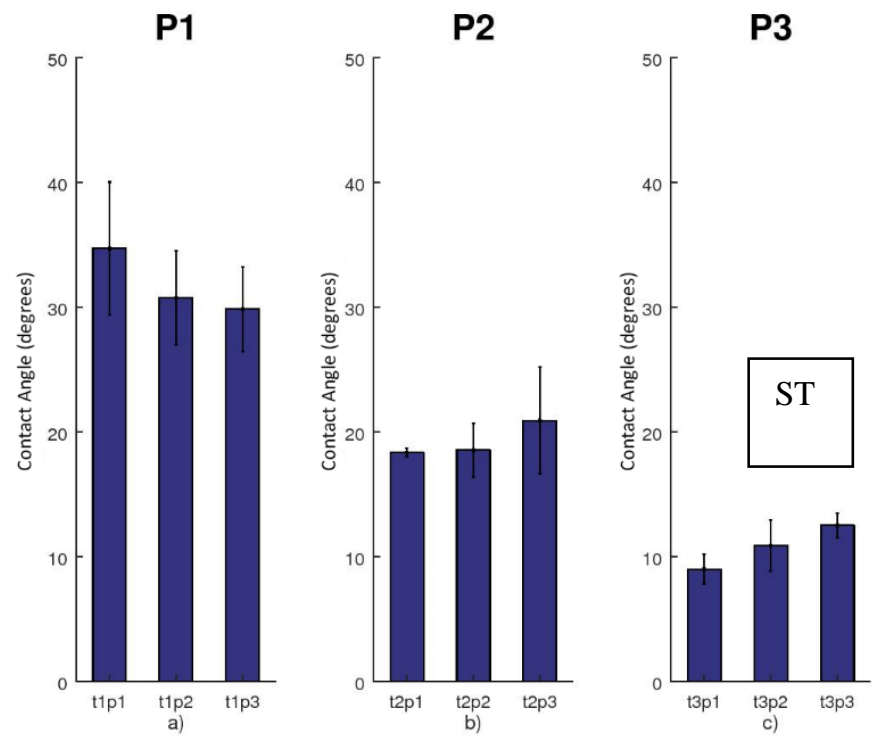

Fig 16:-Comparison of wettability for treatment times $1 \mathrm{~min}(\mathrm{t} 1)$ for positions $\mathrm{P} 1, \mathrm{P} 2$ and $\mathrm{P} 3 \mathrm{a}$ ), 8 min (t2) for positions $\mathrm{P} 1, \mathrm{P} 2$ and $\mathrm{P} 3 \mathrm{~b}$ ) and 16 min (t3) for positions $\mathrm{P} 1, \mathrm{P} 2$ and $\mathrm{P} 3 \mathrm{c}$ ). 


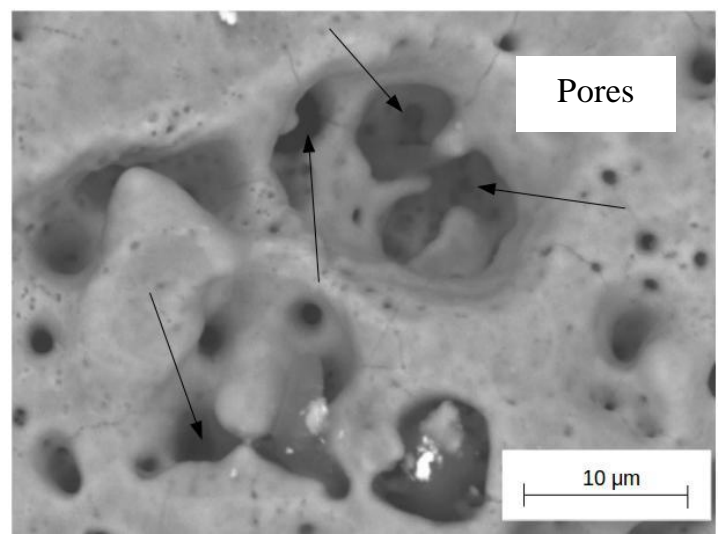

Fig 17: Scanning electron microscopy (SEM) of the sample surface treated by PEO with an increase of 4000X, evidencing the pores.

Initially, elongated grooves and pores were formed and as PEO treatment continued, discharges intensify, therefore, a morphological transition occurs, leading to the formation of circular pores (RENDÓN et al., 2015). The morphology of the circular pores appears to emerge from the fusion of the grooves formed when a certain level of electrical tension was reached. Finally, it was found that the morphological transition is strongly related to the increase of time, strength, density and shape of the electrical discharges generated during the process (GALVIS et al., 2015).

Previous studies show that a larger effective area on the implants surface generated by the nano structuring improve bone-implant contact, an important condition for the success of implants in the biological environment (KULKARNI et al., 2015b).

\section{Conclusions:-}

In this work, the development of a new configuration and study of a ceramic coating by Plasma Electrolytic Oxidation was carried out. Based on the presented results and discussion, one can concluded that simultaneous treatment can be performed within the same electrolytic bath with individual reactors and ensure homogeneous and adherent films to the titanium substrate. The treatment time, in this study, determines the formation mechanism of coating in two main phases. The first was a coating growth and the second an alteration of the surface morphology. This dual behavior can be controlled by the treatment time and, thus, control the distribution and pore sizes. The time of one minute, for the parameters used in this work, produced more adherent coatings. The arrangement of the coating chambers within the same electrolytic bath causes distortions of the electric field and, therefore, resulting in modifications of the coating roughness for the same treatment time. The positioning between the coating chambers produces more uniform coatings. The thickness and porosity degree of a ceramic coating on the titanium surface can be qualified by means of a practical, fast and inexpensive electrical analysis. Ceramic coatings can be made on the surface of dental implants (complex surfaces) with porous and wettable topography with only 1 minute of treatment using a new configuration for the PEO process.

\section{References:-}

1. ALVES JR, C.; GUERRA NETO, C. L. B.; MORAIS, G. H. S.; SILVA, C. F.; HAJEK, V. Nitriding of titanium disks and industrial dental implants using hollow cathode discharge. Surface \& Coatings Technology, v. 194, p. 196-202, 2005.

2. AKTUĞ, S. L. et al. Bioactivity and biocompatibility of hydroxyapatite-based bioceramic coatings on zirconium by plasma electrolytic oxidation. Materials Science and Engineering: C, p. 1020-1027, 2017. ISSN 0928-4931.

3. BANAKH, O. et al. Synthesis by anodic-spark deposition of Ca- and P-containing films on pure titanium and their biological response. Applied Surface Science, v. 378, p. 207-215, 2016. ISSN 0169-4332.

4. BAYATI, M. R.; MOSHFEGH, A. Z.; GOLESTANI-FARD, F. Effect of electrical parameters on morphology, chemical composition, and photoactivity of the nano-porous titania layers synthesized by pulse-microarc oxidation. Electrochimica Acta, v. 55, n. 8, p. 2760-2766, 2010. ISSN 0013-4686. 
5. BECK, U.; LANGE, R.; NEUMANN, H. G. Micro-plasma textured Ti implant surfaces. Biomolecular Engineering, v. 24, n. 1, p. 47-51, 2007. ISSN 1389-0344.

6. BECKER, W. et al. Survival rates and bone level changes around porous oxide coated implants. Clinical implant dentistry and related research, Wiley Online Library, v. 15, n. 5, p. 654-660, 2013.

7. DEHNAVI, V. et al. Effect of duty cycle and applied current frequency on plasma electrolytic oxidation (PEO) coating growth behavior. Surface and Coatings Technology, v. 226, p. 100-107, 2013. ISSN 0257-8972

8. DZHURINSKIY, D. et al. Characterization and corrosion evaluation of $\mathrm{TiO}_{2}: \mathrm{n}-\mathrm{HA}$ coatings on titanium alloy formed by plasma electrolytic oxidation. Surface and Coatings Technology, v. 269, n. Supplement C, p. 258265,2015 .

9. GOVINDARAJAN, T.; SHANDAS, R. A survey of surface modification techniques for next-generation shape memory polymer stent devices. Multidisciplinary Digital Publishing Institute, p. 2309-2331, 2014.

10. GOWTHAM, S.; ARUNNELLAIAPPAN, T.; RAMESHBABU, N. An Investigation on Pulsed DC Plasma Electrolytic Oxidation of cp-Ti and its Corrosion Behaviour in Simulated Body Fluid. Surf. Coat. Technol., v. 301, p. 63-73, 2016.

11. HARIPRASAD, S. et al. Role of electrolyte additives on in-vitro corrosion behavior of DC plasma electrolytic oxidization coatings formed on Cp-Ti. Surface and Coatings Technology, v. 292, p. 20-29, 2016. ISSN 02578972.

12. HENEGAR, A. J. et al. Native oxide transport and removal during atomic layer deposition of tio2 films on gaas (100) surfaces. ACS applied materials \& interfaces, ACS Publications, v. 8, n. 3, p. 1667-1675, 2016.

13. KASEMO, B. Surface Science, vol. 500, p. 656, 2002.

14. K, V. et al. Role of electrolyte chemistry on electronic and in vitro electrochemical properties of micro-arc oxidized titania films on Cp Ti. Electrochimica Acta, v. 105, n. Supplement C, p. 468-480, 2013. ISSN 00134686.

15. KHANMOHAMMADI, H. et al. The Influence of Current Density and Frequency on the Microstructure and Corrosion Behavior of Plasma Electrolytic Oxidation Coatings on Ti6Al4V. Journal of Materials Engineering and Performance, v. 26, n. 2, p. 931-944, 2017. ISSN 1059-9495.

16. LI, Q. et al. Correlations between the growth mechanism and properties of micro-arc oxidation coatings on titanium alloy: Effects of electrolytes. Surface and Coatings Technology, v. 316, n. Supplement C, p. 162-170, 2017. ISSN 0257-8972.

17. LIU, S. et al. Formation mechanism and adhesive strength of a hydroxyapatite/TiO2 composite coating on a titanium surface prepared by micro-arc oxidation. Applied Surface Science, v. 362, n. Supplement C, p. 109114, 2016. ISSN 0169-4332.

18. MOHSENI, E.; ZALNEZHAD, E.; BUSHROA, A. R. Comparative investigation on the adhesion of hydroxyapatite coating on ti6al4v implant: A review paper. International Journal of Adhesion and Adhesives, Elsevier, v. 48, p. 238-257, 2014.

19. MU, M. et al. One-step preparation of TiO2/MoS2 composite coating on Ti6Al4V alloy by plasma electrolytic oxidation and its tribological properties. Surface and Coatings Technology, v. 214, n. Supplement C, p. 124130, 2013. ISSN 0257-8972.

20. PAHL, G.; Beitz, W. Engineering Design: A Systematic Approach. Editora Springer Science \& Business Media, Ed. 2, 2013. ISBN 1447135814, 9781447135814.

21. PARFENOV, E. V. et al. Towards smart electrolytic plasma technologies: An overview of methodological approaches to process modelling. Surface and Coatings Technology, v. 269, n. Supplement C, p. 2-22, 2015. ISSN 0257-8972.

22. PIRES, A. L. R.; BIERHALZ, A. C. K.; MORAES, A. M.; Biomateriais: Tipos, aplicações e mercado. Química Nova, vol. 38, n. 7, p. 957-971, 2015.

23. PULEO, D.A.; NANCI, A.; Understanding and controlling the bone-implant interface. Biomaterials, v.20, n.2324, p.2311-2321, 1999.

24. QIAO, L. P. et al. The entrance mechanism of calcium and phosphorus elements into micro arc oxidation coatings developed on Ti6A14V alloy. Surface and Coatings Technology, v. 285, n. Supplement C, p. 187-196, 2016. ISSN 0257-8972.

25. QIU, Z.-Y. et al. Advances in the surface modification techniques of bone-related implants for last 10 years. Regen. Biomater., Oxford University Press, v. 1, n. 1, p. 67-79, nov 2014. ISSN 2056-3418.

26. RAJ, V., MUBARAK ALI, M. Formation of ceramic alumina nanocomposite coatings on aluminium for enhanced corrosion resistance. Journal of Materials Processing Technology, v. 209, p. 5341-5352, 2009.

27. SCHWARTZ, Z. \& BOYAN, B.D. Underlying mechanisms at the bone-biomaterial interface. J. Cell Biochem., v.56, n.3, p.340-347, 1994. 
28. SHOKOUHFAR, M.; ALLAHKARAM, S. R. Formation mechanism and surface characterization of ceramic composite coatings on pure titanium prepared by micro-arc oxidation in electrolytes containing nanoparticles. Surface and Coatings Technology, v. 291, n. Supplement C, p. 396-405, 2016. ISSN 0257-8972.

29. SILVA, M. A. M.; GUERRA NETO, C. L. B.; NUNES FILHO, A.; FREITAS, D. O.; BRAZ, D. C.; ALVES JR, C. Influencie of topography on plasma treated titanium surface wettability. Surface \& Coatings Technology, v. 235, p. 447-453, 2013.

30. SOWA, M. et al. Bioactivity of coatings formed on $\mathrm{Ti}-13 \mathrm{Nb}-13 \mathrm{Zr}$ alloy using plasma electrolytic oxidation. Materials Science and Engineering: C, v. 49, p. 159-173, abr. 2015. ISSN 0928-4931.

31. SRINIVASAN P. B., BLAWERT C., DIETZEL W. Dry sliding wear behaviour of plasma electrolytic oxidation coated AZ91 cast magnesium alloy, Wear, v. 266, p.1241-1247, 2009.

32. TRAN, K. T.; NGUYEN, T. D. Lithography based methods to manufacture biomaterials at small scales. J. Sci. Adv. Mater. Devices, Elsevier, v. 2, n. 1, p. 1-14, mar2017. ISSN 24682179.

33. VENKATESWARLU, K. et al. Role of electrolyte additives on in-vitro electrochemical behavior of micro arc oxidized titania films on Cp Ti. Applied Surface Science, v. 258, n. 18, p. 6853-6863, 2012. ISSN 0169-4332.

34. WANG, H.-Y. et al. Preparation and properties of plasma electrolytic oxidation coating on sandblasted pure titanium by a combination treatment. Materials Science and Engineering: C, v. 42, n. Supplement C, p. 657664, set. 2014. ISSN 0928-4931.

35. WANG, Y. et al. Review of the biocompatibility of micro-arc oxidation coated titanium alloys. Materials \& Design, v. 85, n. Supplement C, p. 640-652, nov. 2015. ISSN 0264-1275.

36. WANG, Y.-H. et al. Dependence of the infrared emissivity on SiC content and microstructure of microarc oxidation ceramic coatings formed in $\mathrm{Na} 2 \mathrm{SiO} 3$ electrolyte. Applied Surface Science, jun. 2017.

37. WHEELER, J. M. et al. Evaluation of micromechanical behaviour of plasma electrolytic oxidation (PEO) coatings on Ti-6Al-4V. Surface and Coatings Technology, v. 204, n. 21, p. 3399-3409, 2010.

38. WILLIAMSON, R. S. et al. Effect of duty cycle on the crystallinity, pore size, surface roughness and corrosion resistance of the anodized surface on titanium. Surface and Coatings Technology, v. 277, p. 278-288, 2015. ISSN 0257-8972.

39. WISMEYER, D.; van WASS, M.; VERMEEREN, J.I. Overdentures supported by ITI implants: A 6,5-year evaluation of patient satisfaction and prosthetic aftercare. Int. J. Oral Maxillofac. Impl., v.10, n.6, p.744-749, 1995.

40. YAVARI, S. A. et al. Biofunctional surfaces by plasma electrolytic oxidation on titanium biomedical alloys. Surface Engineering, v. 32, n. 6, p. 411-417, 2016. ISSN 0267-0844.

41. YEUNG, W. K. et al. In vitro biological response of plasma electrolytically oxidized and plasma-sprayed hydroxyapatite coatings on Ti-6Al-4V alloy. Journal of Biomedical Materials Research Part B: Applied Biomaterials, v. 101B, n. 6, p. 939-949, 2013. ISSN 1552-4981.

42. YEUNG, W. K. Investigation of Plasma Electrolytic Oxidation Processes for Production of Porous Biocompatible Coatings on Ti Alloys. Tese (phd) — University of Sheffield, mar. 2016.

43. YU, H.; CHEN, S.; CAO, P. Synergistic bactericidal effects and mechanisms of low intensity ultrasound and antibiotics against bacteria a review. Ultrasonics Sonochemistry, v. 19, n. 3, p. 377-382, maio 2012. ISSN 1873-2828.

44. ZHAO, Y.; YEUNG, K. W.; CHU, P. K. Functionalization of biomedical materials using plasma and related technologies. Appl. Surf. Sci., North-Holland, v. 310, p. 11-18, aug 2014. ISSN 01694332.

45. ZHOU, T. et al. Surface functionalization of biomaterials by radical polymerization. Prog. Mater. Sci., Pergamon, v. 83, p. 191-235, oct 2016. ISSN 00796425. 